\title{
Pure Ground-Glass Pulmonary Nodule
}

National Cancer Institute

\section{Source}

National Cancer Institute. Pure Ground-Glass Pulmonary Nodule. NCI Thesaurus. Code C138148.

A term that refers to a pulmonary nodule in which there are no completely obscured parenchymal areas by the ground-glass opacity on CT scan examination. 